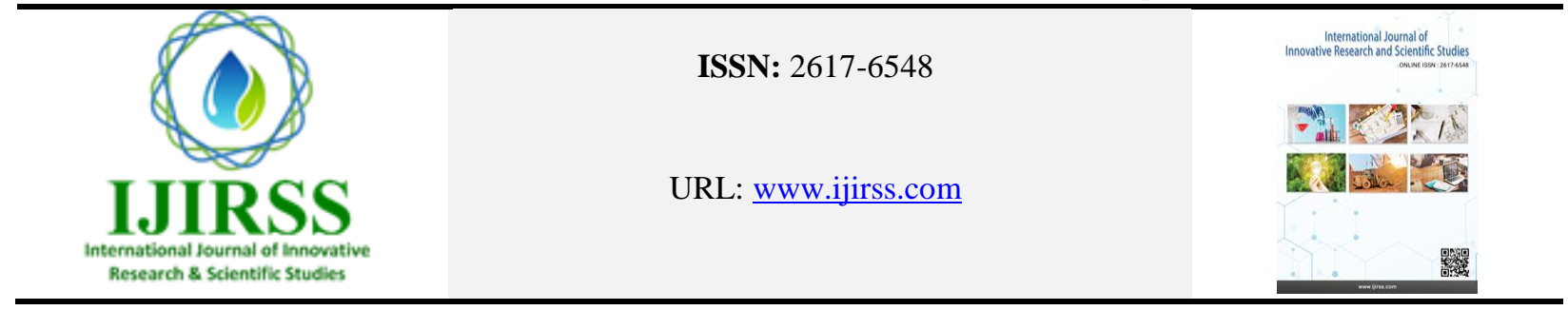

\title{
Thin-Layer Mathematical Modeling of Apple Slices Drying, Under Open Sun and Cabinet Solar Dryer
}

\author{
Abdul Wasim Noori ${ }^{12^{*}}$, Mohammad Jafar Royen ${ }^{1,2}$, Juma Haydary ${ }^{1}$, \\ ${ }^{1}$ Institute of Chemical and Environmental Engineering, Slovak University of Technology in Bratislava, 1Radlinského 9, 81237 Bratislava \\ ${ }^{2}$ Faculty of Chemical Technology, Kabul Polytechnic University, Kart-e Mamoorin, 5th District, Kabul, 2 Afghanistan. \\ *Corresponding author: Abdul Wasim Noori (juma.haydary@stuba.sk)
}

\begin{abstract}
This paper aims to investigate the effect of climate conditions such us ambient temperature, humidity, pressure, sun radiation and pollution on sliced apples quality and drying time which are dried in an indirect forced cabinet solar drying (IFCSD) and open sum drying (OSD) systems. Both experiments were implemented in the same place (Kabul, Afghanistan) and time. The IFCSD yielded for saving time is $42.8 \%$ which is more effective than drying in the OSD system. Simultaneously with the decreasing of sliced apples weight from $512.9 \mathrm{~g}$ down to $73.9 \mathrm{~g}$, the water activity is decreased from 0.955 down to 0.355 in the IFCSD system, and in the OSD system, the sample weight is decreased form $512.6 \mathrm{~g}$ down to $78.4 \mathrm{~g}$ and the water activity was decreased from 0.955 down to 0.411 . On the experiment day the average sun radiation was $571 \mathrm{w} / \mathrm{m} 2$. The pressure drop between inlet and outlet of the dryer was $0.1 \mathrm{kPa}$. From all 11 applied thinlayer drying models the Page, Approximation diffusion, Verma et al and Midilli and Kacuk models are more fitted to our data. Likewise, the mathematical models performances were investigated by comparing the coefficient of determination (R2), reduced chi-square (X2) and root mean square error (RMSE) coefficients.
\end{abstract}

Keywords: Apple, Cabinet solar drying, Open sun drying, Mathematical models, Climate conditions.

DOI: $10.53894 /$ ijirss.v4i2.55

Funding: This work was realized thanks to the support of the Slovak Aid projects SAMRS/AFG/2018/01/01 and SAMRS/AFG/2020/01/01 and it was supported by the project APVV-19-0170 provided by the Slovak Research and Development Agency.

History: Received: 8 January 2021/Revised: 12 February 2021/Accepted: 10 March 2021/Published: 30 March 2021

Licensed: This work is licensed under a Creative Commons Attribution 4.0 License $(\mathrm{cc})$ Er

Acknowledgement: All authors contributed equally to the conception and design of the study.

Competing Interests: The authors declare that they have no conflict of interests.

Transparency: The authors confirm that the manuscript is an honest, accurate, and transparent account of the study was reported; that no vital features of the study have been omitted; and that any discrepancies from the study as planned have been explained.

Ethical: This study follows all ethical practices during writing.

\section{Introduction}

Vegetable and fruits are seasonable agriculture products. Vitamins, minerals and fibers are the essential compounds of these products for human nutrition. Due to the presence of high moisture, vegetable and fruits are exposed to microbial spoilage sooner, and their shelf life is very short [1]. Apples (Malus domestica) are among the tree fruits that are grown and produced in most countries of the world. This fruit is rich in vitamins, minerals and fiber, and also it is consumed in various forms such as fresh juice, dried and compote. Apples are also used in the manufacturing industries of jams, vinegar, etc. [2]. Afghanistan's climate is also very suitable for growing apple seedlings and apple production. Eleven different types of 
apples such as Red Chief, Blushing Gold, Royal Gala, Double Red Delicious, Michgla, Modal Gala, Fuji, Galaxy and Saturn have the highest yield in Afghanistan and most of them are produced in the central provinces $[3,4]$.

The most well-known and easiest method for preservation of the fruit and vegetables is drying. Drying is an energy intensive process for water reducing from the sample. As the agricultural crops dries, not only the shelf-life become longer but also reducing the microbial activities compared to the fresh products. Additionally, the transportation, packaging, and storage costs are reduced as well. In recent years, various drying methods for drying agricultural products have been studied, which include: spray drying [5] freeze drying vacuum drying [6], microwave drying and solar drying methods such as open sun drying (OSD) [7] or cabinet solar drying (CSD) [8]. Supplying power required for drying is one of the fundamental problems in the drying process which constitutes the basic economics of the drying process. Solar drying of agricultural crops is the simplest and cheapest way for preserving such products . Humans have been familiar with OSD for centuries. They used this method to dry meat, cereals, fruits, vegetables, etc.

Afghanistan is a landlocked and upland country, which is located in the central of the Asia whit high temperature ,low humidity and pressure. With more than 300 sunny days a year, Afghanistan is one of the best countries for solar drying. During the seasons of the year, on average, the solar radiation were changed from $2,38 \mathrm{kWh} / \mathrm{m}^{2} /$ day up to $7.84 \mathrm{kWh} / \mathrm{m}^{2} /$ day [9]. Developing or underdevelopment countries such as Afghanistan still used OSD to dry meat and all kinds of agricultural products. Utilization of OSD is common as it is easy to use, inexpensive, and energy source is accessible anywhere. Main focus today is on drying development using renewable sources, especially solar energy. In the late and early 20th and 21st centuries, OSD and CSD systems for drying of different products have been studied by many researchers. Various aspects of open sun drying have been evaluated in the work of these researchers [7, 10-12]. A wide variety of solar dryers whit different functions have been designed and developed by many researchers [13-15]. In the recent years many researcher are studied about apple drying $[16,17]$. During the apple drying process into the designed heat pump and solar dryers are experimentally compared and analyzed. The heat pump dryer system drying time is shorter than the solar drying system. Henderson and Pabis mathematical models are more suitable for bout drying system. Blanco-Cano, et al. [18] have studied the use of many thin-layer Granny Smith apple drying models in indirect solar dryers. They found that Wang-Sing model is more fitted for conducted thermogravimetric analyzer (TGA) for different constant drying temperatures. Sacilik, et al. [19] evaluated dried apple slices with different thickness and temperature. They determined that the dried product whit this device has good quality. Using mean relative percent error, root mean square error and reduced chi-square coefficients determined the logarithmic model is the most suitable model among the 10 applied models . Drying of apple slices in a solar dryer with a thermal energy storage system was studied by Atalay, et al. [20]. By the installation of thermal energy storage, they were able to recover 50 to $60 \%$ of the wasted energy. This unit had the ability to decrease $76.8 \%$ energy consumption among the studied literature devices. They also developed and evaluated some models for apple slices whit 5 $\mathrm{mm}$ thickness under the constant temperatures. The fitted model for apple slice drying with this system is diffusion approximation between all applied models. Thin layer drying models are used for many others product drying like Marine products, Cereals, leafy vegetable, fruits etc. [3,21,22]. The objective of this study is the comparison of drying time, effect of climatic conditions (temperature, humidity, pressure and air pollution) typical for geographical locations with an altitude of 1800 to $2000 \mathrm{~m}$ above the sea level on dried product quality, reducing of water activity after each sampling, of the open sun drying and indirect forced cabinet solar drying for apple (Blushing Gold) slices. Another objective of this work was to select the most appropriate model (in terms of fitting ability) among the eleven models used in this study to describe the drying of thin layers slices under OSD, IFCSD and climate conditions used.

\section{Materials and Methods}

\subsection{Sample preparation}

The fresh apples (Blushing Gold) used for this study were purchased from the fresh fruits and vegetable market in Kabul, Afghanistan in the harvesting time. After selecting the uniform size of apples with diameters ranging from 6 to 8 $\mathrm{cm}$, the apples were washed with tap water and cut it into $5 \pm 0.1 \mathrm{~mm}$ thickness horizontally and semi circularly with a stainless steel manual cutter. For each experiments run (OSD and IFCSD) prepared $500 \pm 2 \mathrm{~g}$ sliced apples and placed in the IFCSD trays and OSD plastic basket; the tray was placed into the IFCSD device and the plastic basket was exposed to the sunlight close to device for OSD experiment. The apple slices were weighted on digital scale

\subsection{Experimental procedure}

\subsubsection{IFCSD system}

The current indirect forced cabinet solar drying (IFCSD) is a complementary system where all the energy used is supplied from renewable sources. This system is consisting of three essential parts: dryer chamber, solar collector and photovoltaic solar panel for centrifugal air blower and exhaust fan power supply. The wooden rectangular drying chamber is $1200 \times 600 \times 400 \mathrm{~mm}$. The dryer chamber has four trays with a total capacity of $2000 \mathrm{~g}$ of sliced apple in one run. The flat solar collector dimensions are $1500 \times 600 \times 100 \mathrm{~mm}$ with a $0.9 \mathrm{~m}^{2}$ surface area. Helix shape aluminum pipe with 10.5 $\mathrm{m}$ long and $55 \times 35 \mathrm{~mm}$ rectangular cross-section are the main component of the collector. The surface of the pipes is covered with heat-absorbing and non-reflective materials layer. In order to strengthen the air velocity in the collector inlet and outlet of the drying chamber, DC blower and exhaust fan have been installed. For energy, supplying of the blower and exhaust, A 240 watt photovoltaic panel is used Figure (a-1).

For measuring of the parameters, Testo $176 \mathrm{~T} 4$ were used for temperature Testo $176 \mathrm{P} 1$ for pressure, temperature and humidity and Testo 405 for air velocity data loggers are used. All these instruments are produced by Testo SE \& Co. KGaA. 


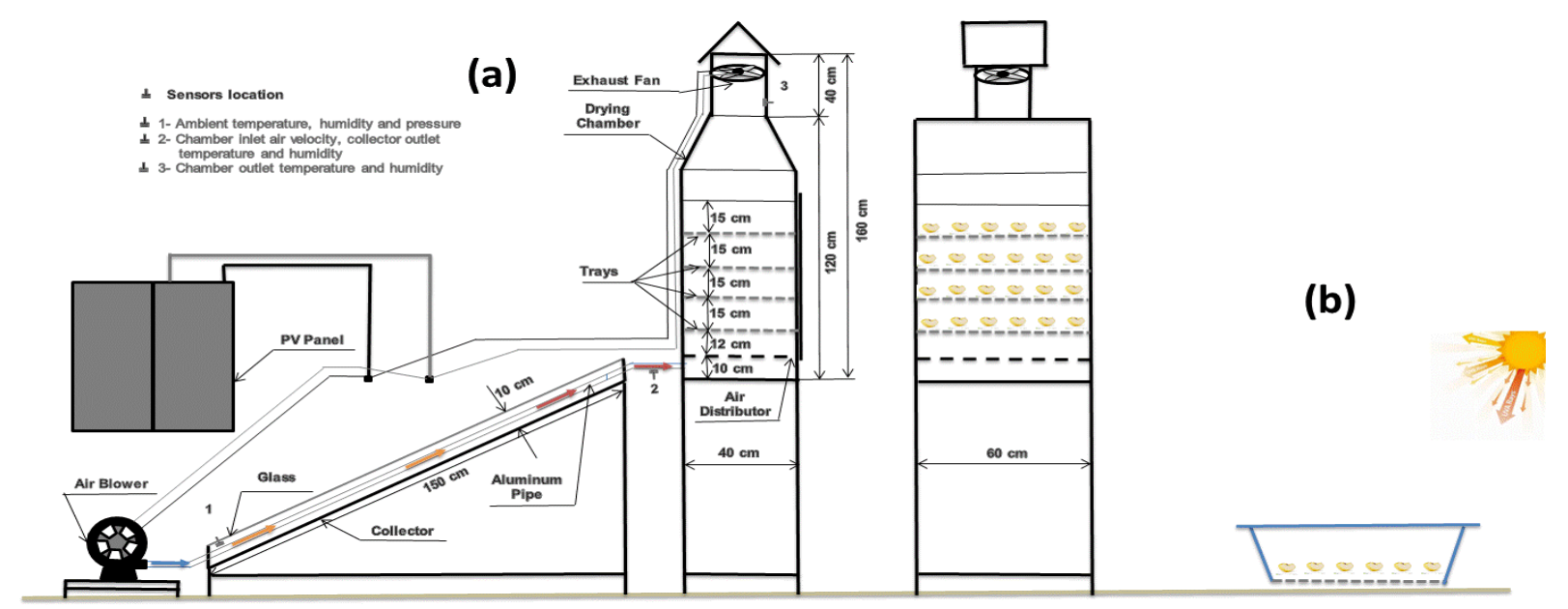

Figure-1.

Schematic description of the IFCSD (a) and OSD (b) complete systems.

\subsubsection{OSD system}

Experiments of OSD were also performed like IFCSD at the middle of October, on sunny days from 9:00 am to 5:00 pm when ambient temperature varied between 18 and $29{ }^{\circ} \mathrm{C}$ and average air velocity was $1.8 \mathrm{~m} / \mathrm{s}$. In these experiments, $500 \mathrm{~g}$ sliced apple were placed in a plastic basket with the inner dimensions of $500 \times 350 \times 100 \mathrm{~mm}$ and exposed to direct sun radiation, same climate conditions and the same thickness of the sample as in the IFCSD device were considered (Figure (1-b).

\subsection{Experimental procedure}

The IFCSD device trays and OSD plastic basket washing with tap water and cleaning of the chamber inside, collector and PV solar penal surface was the first step of our experiment startup. The second step was the measuring and determination of initial water activity and moisture content of fresh apple slices. Water activity analyzer (LABTOUCH aw SET ADVANCED, Novasina AG, Switzerland) and analytical moisture analyzer (VWR MBT160 moisture analyzer, VWR International, Italy capacity: 0.001-160 g) devices were respectively used for measuring and determination of fresh apple initial water activity and moisture content.

After the samples were moved in the trays of solar dryer device and the plastic basket for OPS drying, by turning on the blower and exhaust switch, the measurement starts. During every two hours sampling, simultaneously with sampling, ambient parameters (temperature, pressure, solar radiation intensity and humidity), parameters in the device (temperature at the outlet of the collector, air velocity at the inlet of the chamber (50.8 mm Ø-pipe), humidity at the outlet of the chamber, pressure at the outlet of the chamber) and parameters in the laboratory (sample weight, sample moisture and water activity) were also measured and recorded.

\subsection{Mathematical modeling}

Various thin layer mathematical models were proposed in the literature [1,23-26]. In this work the models shown in $\underline{\text { Table } 1}$ were tested for drying of apple slice in both OSD and IFCSD systems.

Table-1.

Selected thin layer mathematical models

\begin{tabular}{l|l|l|l}
\hline No & Model name & Model & Reference \\
\hline 1 & Newton & $M R=\exp (-k t)$ & Bahammou, et al. [25] \\
\hline 2 & Page & $M R=\exp \left(-k t^{n}\right)$ & Koua, et al. [23] \\
\hline 3 & Modified Page & $M R=\exp [-(k t)]^{n}$ & Koua, et al. [23] \\
\hline 4 & Logarithmic & $M R=a \exp (-k t)+c$ & Ali, et al. [27] \\
\hline 5 & Henderson and Pabis & $M R=a \exp (-k t)$ & Zhou and Jin [26] \\
\hline 6 & Tow-term & $M R=a \exp \left(-k_{0} t\right)+b \exp \left(-k_{1} t\right)$ & Lahsasni, et al. [28] \\
\hline 7 & Two term exponential & $M R=a \exp (-k t)+(1-a) \exp (-k a t)$ & Akpinar and Bicer [24] \\
\hline 8 & Midilli et al & $M R=a \exp (-k t)^{n}+b t$ & Zhou and Jin [26] \\
\hline
\end{tabular}




\begin{tabular}{l|l|l|l}
\hline 9 & Approximation of diffusion & $M R=a \exp (-k t)+(1-a) \exp (-k b t)$ & Sacilik, et al. [19] \\
\hline 10 & Verma et al & $M R=a \exp (-k t)+(1-a) \exp (-g t)$ & Toğrul and Pehlivan [22] \\
\hline 11 & Midilli and Kucuk & $M R=a \exp \left(-k t^{n}\right)+b t$ & Mohamed, et al. [29] \\
\hline
\end{tabular}

In the all models $M R$ is moisture ratio, $t$ is time, $k$ is drying rate constant, $a, b, c, g$ and $n$ are model coefficients. Equation 1 is used for calculation of $M R$ for apple drying [3].

$$
M R=\frac{M_{t}-M_{e}}{M_{0}-M_{e}}
$$

The initial and final moisture content of sliced apple has been funded with Equations 2,3 [28].

$$
\begin{aligned}
& M_{0}=\frac{m_{i}-m_{d}}{m_{d}} \\
& M_{f}=\frac{m_{w}-m_{d}}{m_{d}}
\end{aligned}
$$

In these equations, $M_{0} M_{f}, M_{t}$, and $M_{e}$, represent initial moisture content $\left(\mathrm{kg} \mathrm{H}_{2} \mathrm{O} / \mathrm{kg}\right.$ dry matter), final moisture content ( $\mathrm{kg} \mathrm{H}_{2} \mathrm{O} / \mathrm{kg}$ dry matter), transient moisture content $\left(\mathrm{kg} \mathrm{H}_{2} \mathrm{O} / \mathrm{kg}\right.$ dry matter) and equilibrium moisture content $\left(\mathrm{kg} \mathrm{H}_{2} \mathrm{O} / \mathrm{kg}\right.$ dry matter); $m_{i}, m_{d}$ and $m_{w}$ represent initial mass $(\mathrm{kg})$, dry material mass $(\mathrm{kg})$ and mass of wet mater after drying process.

For selecting of the best fitted mathematical models for apple slices drying, is necessary to calculate these three important statistical parameters: correlation coefficient $\left(R^{2}\right)$ Equation 4 chi-square $\left(X^{2}\right)$ Equation 5, and root mean square error (RMSE) Equation 6. The model with the highest value of $R^{2}$ and lowest $X^{2}$ and $R M S E$ indicate the best fit of the model. The empirical constants for the models were obtained using Microsoft office Excel Solver, [3, 23, 25, 27].

$$
\begin{array}{r}
R^{2}=1-\frac{\sum_{i=1}^{n}\left(M R_{\text {pre }, i}-M R_{\text {exp }, i}\right)^{2}}{\sum_{i=1}^{n}\left(M R_{\text {exp }, i}-M R_{\text {exp }, a v}\right)^{2}} \\
X^{2}=\frac{\sum_{i=1}^{n}\left(M R_{\text {pre }, i}-M R_{\text {exp }, i}\right)^{2}}{N-z} \\
\text { RMSE }=\left[\frac{1}{N} \sum_{i=1}^{n}\left(M R_{\text {pre }, i}-M R_{\text {exp }, i}\right)\right]^{1 / 2}
\end{array}
$$

In these equations, MRexp, $i$ represents the $i$ th experimentally observed normalized moisture ratio, MRpre, $i$ represents the ith predicted value, MRex, $a v$ is average of normalized $M R$ of experimental points, $N$ is the number of observations and $z$ is the number of constants in the model.

\section{Results and Discussion}

\subsection{Effect of Ambient Conditions on Drying}

Figure 2 shows the ambient and collector outlet temperature changes simultaneously with the change in the intensity of sun radiation. Usually existence pieces of the clouds in the sky have caused inconsistencies in the curves of the first day (first $6 \mathrm{~h}$ ). The second day (from 8 to $16 \mathrm{~h}$ ) data show the same changes for all three curves. By increasing of the sunlight intensity from 182 up to $972 \mathrm{w} / \mathrm{m}^{2}$ the ambient temperature increased from 22.4 up to $29.1{ }^{\circ} \mathrm{C}$ and collector outlet temperature increased from $33{ }^{\circ} \mathrm{C}$ to $55.4^{\circ} \mathrm{C}$. The collector heating efficiency was $90.4 \%$ at maximum against ambient air temperature. Sun radiation intensity of Kabul, Afghanistan during the experiment time was $571 \mathrm{w} / \mathrm{m}^{2}$ in the average case.

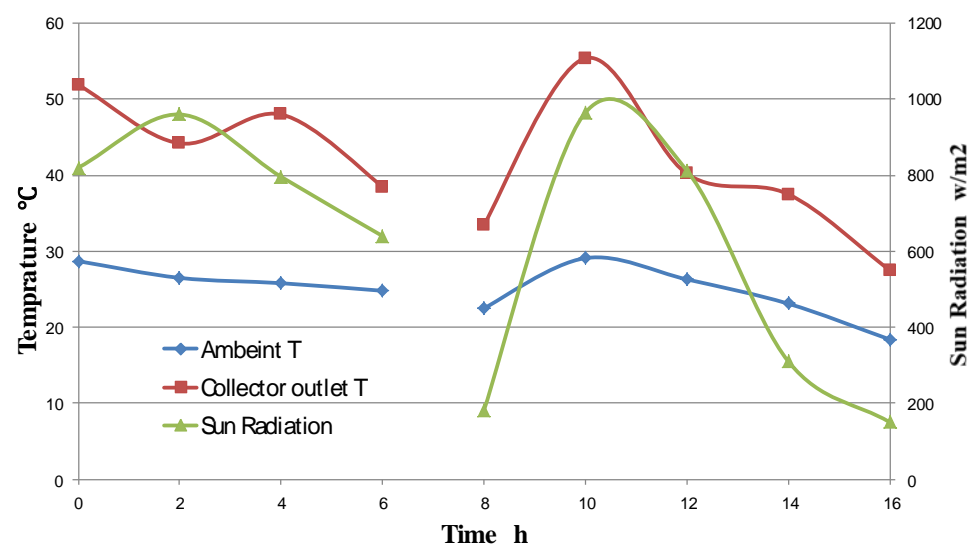

Figure-2.

Ambient temperature $\left({ }^{\circ} \mathrm{C}\right)$, collector outlet temperature $\left({ }^{\circ} \mathrm{C}\right)$ and sun radiation $\left(\mathrm{w} / \mathrm{m}^{2}\right)$.versus drying time $(\mathrm{h})$

Ambient humidity changes are inversely related to ambient temperature changes. Figure 3 . proves and illustrates this point; when the ambient temperature increased the ambient humidity decreased. During experiment the ambient temperature changed from $22.4^{\circ} \mathrm{C}$ to $29.1^{\circ} \mathrm{C}$ while the air relative humidity was changed from $18.9 \%$ to $34.1 \%$. 


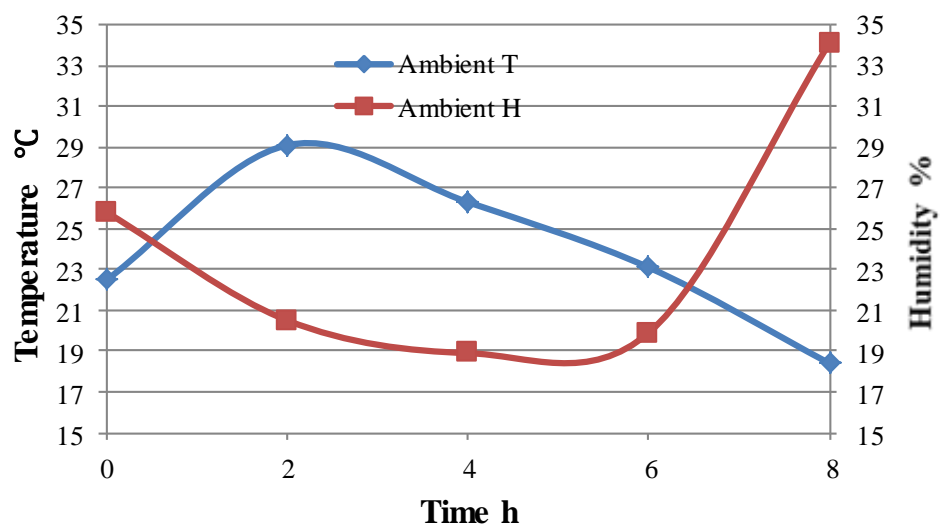

Figure-3.

Ambient air relative humidity $(\%)$ and temperature $\left({ }^{\circ} \mathrm{C}\right)$ versus drying time $(\mathrm{h})$.

By using the data obtained experimentally on the mass loss of the sample and the Equations 1,2 and 3, the transient moisture content of the sample (d.b) and the moisture ratio (MR) were calculated. The change of the product moisture content measured by a moisture analyzer is presented. Figure 4 illustrates that the IFCSD has a $42.8 \%$ time efficiency against OSD. This figure also represents the samples mass drop $(H)$ for both systems during the night $(25 \%$ for OSD and $6 \%$ for IFCSD). OSD higher mass drop is related to the effect of airflow in the open space, which the airflow is not so effected for IFCSD system.

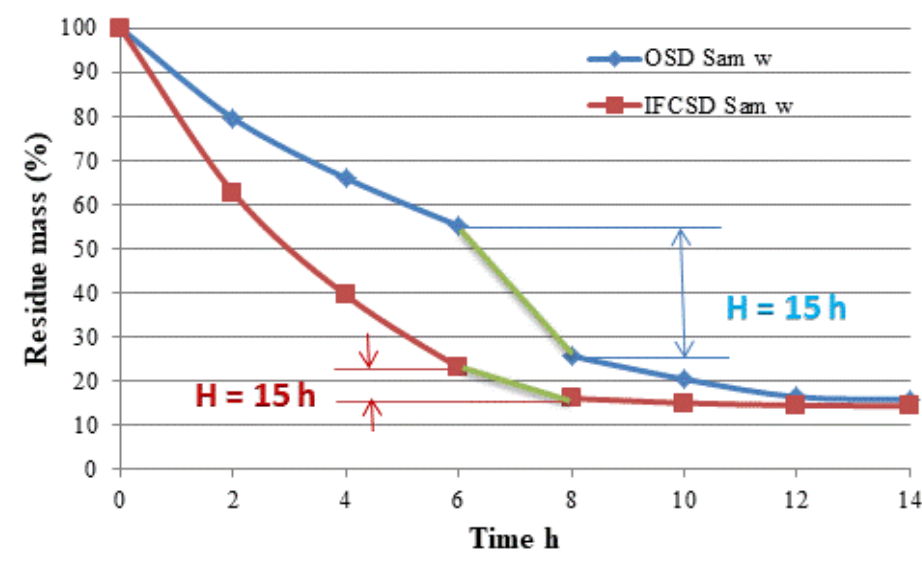

Figure-4.

Variation of sample residue mass as a function of drying time (h).

The change of the product water activity was measured by a water activity analyzer. The initial water activity of apple slices was 0.955 which decreased down to 0.355 with IFCSD and to 0.495 with OSD in end of second experimental day (Figure 5).

The water activity curve (Figure 5) of dried apples in the open sun drying shows that at the end of the second day of experiment, the product water activity is close to 0.5 , which means that the product is still exposed to microbial spoilage, with a slight absorption of ambient humidity, the shelf life of the dried product is cam decreased. Therefore, in the case of OSD, we continued the experiment for the third day. As shown in Figure 6. In the first hours of drying time in the third experimental day, it shows opposite movement and the products water activity started increasing, which means that the dried product started to absorb water from the ambient humid air after the sunset when the air relative humidity increased. At repeated measurements, this phenomenon has reappeared. 


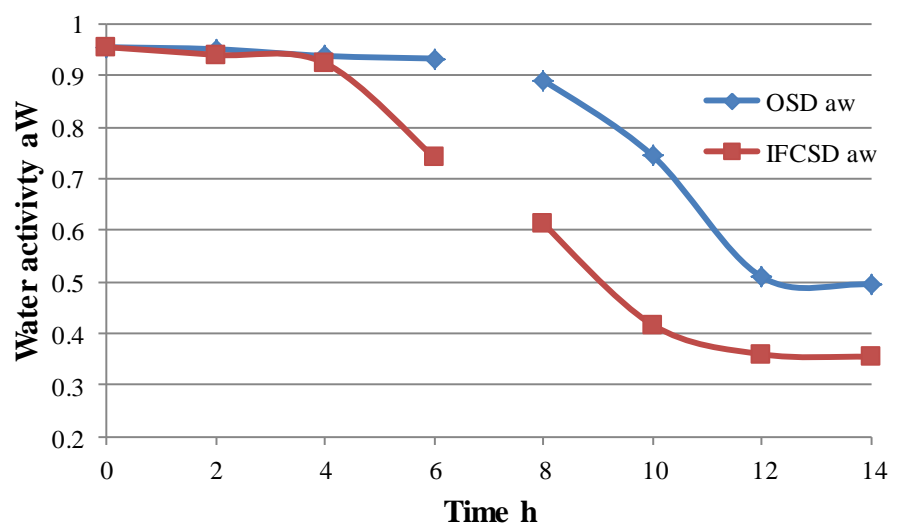

Figure-5.

Product water activity (aW) versus drying time (h) for two days

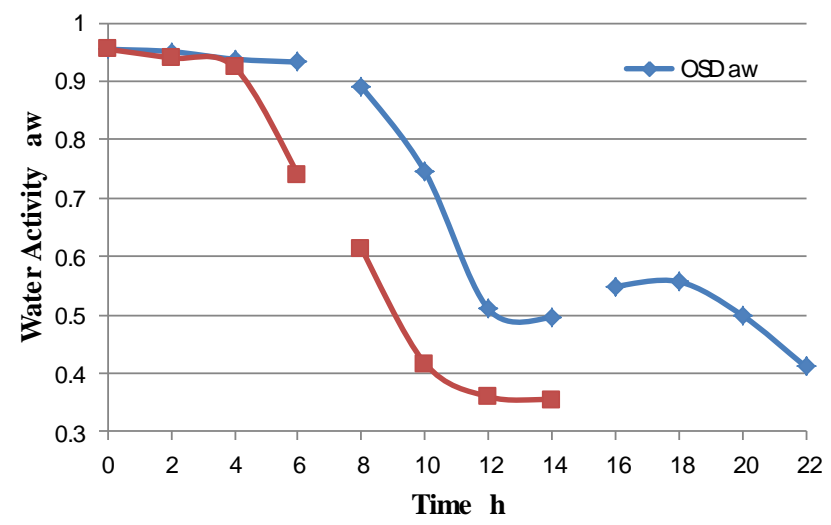

Figure-6.

Product water activity (aW) versus drying time (h) for three days

Figure 7 illustrates the whole Blushing Gold fresh apple (7-a), fresh slices, OSD and IFCSD dry apple slices (7-b, 7-c, 7-d, 7-e). The 7-b and 7-e samples are dried whit IFCSD system and 7-c and 7-d are dried whit OSD. All last four pictures are representing the effect of sunlight and air pollutions on OSD dried product, pictures 7-c and 7-d. The IFCSD dried product better color quality of product is clearly visible in pictures 7-b and 7-e.
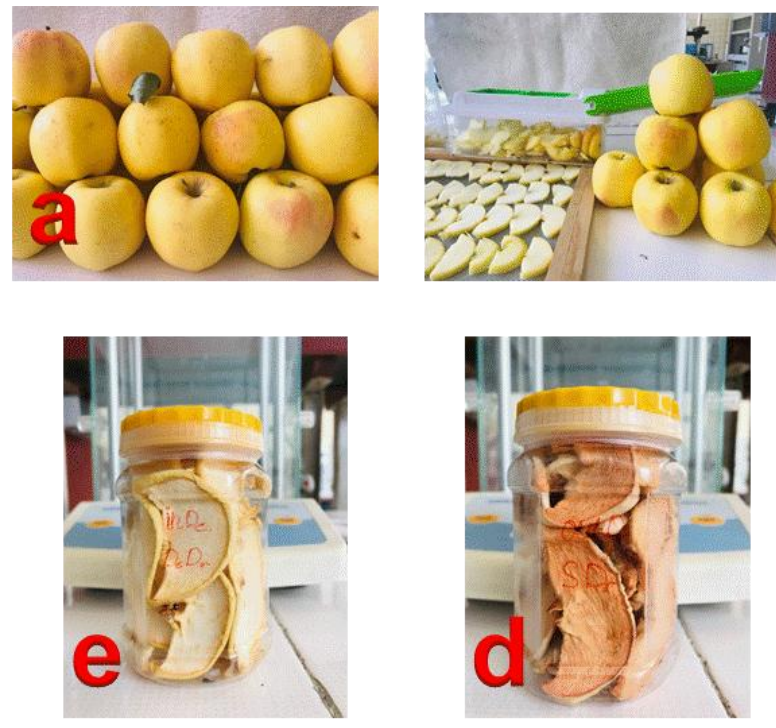
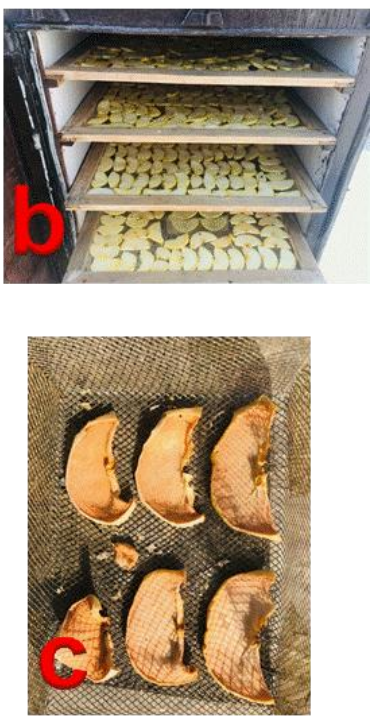

Figure-7.

OSD and IFCSD Sample preparation and color comparison of apple slices: a- fresh apples (Blushing Gold), b, e- IFCSD products, c, d- OSD products.

Ambient air pollution is a major quality problem for OSD dry products in Afghanistan; the air pollutants reduce the quality of dried products in the OSD system. The dried apple slices placed under a microscope which is equipped with an 
imaging system and the surface of the dried samples were photographed Figure 8 stains on the surface of dried apple slices in the OSD indicate the presence of air pollutants that accumulate on the dried apple slices and cause a change in color and even the taste of the product. Therefore, based on the photos taken of both products (Figure 8), it can be said that; the dried products in the IFCSD have good quality and taste than the dried products in the OSD.

IFCSD
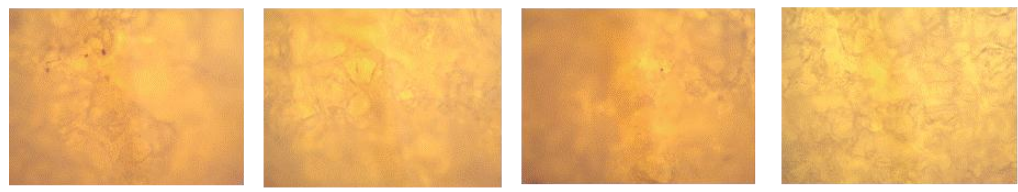

OSD
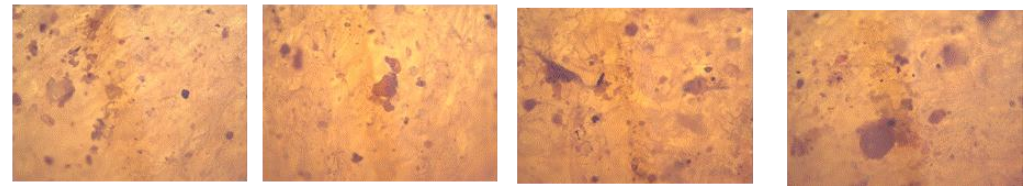

Figure-8.

Air pollution effect on dry apple sliced OSD and IFCSD product.

\subsection{Mathematical model selection}

In order to select a convenient thin-layer model for drying apple slices in the IFCSD and OSD,11 empirical models given in Table 1, have been used to compare the experimental and theoretical moisture ratio data versus time. In Figures 9 and 10 the comparison of experimental data with predicted data by Page, Approximation diffusion, Verma et al., and Midilli Kacuk models are shown.

From the comparison of Figure 9 with Figure 10, it can be concluded that the drying in the IFCSD take place under stabilized conditions and thin layer models better describe the behavior of experimental data; the experimental data $\left(M R_{\text {exp }}\right.$, curve) are very close to the calculated theoretical data $\left(M R_{\text {pre }}\right.$, curve). In the case of open sun drying the drying conditions are not stable; experimental data are more scattered, for this reason the thin layer model do not provide perfect fitting of experimental data.
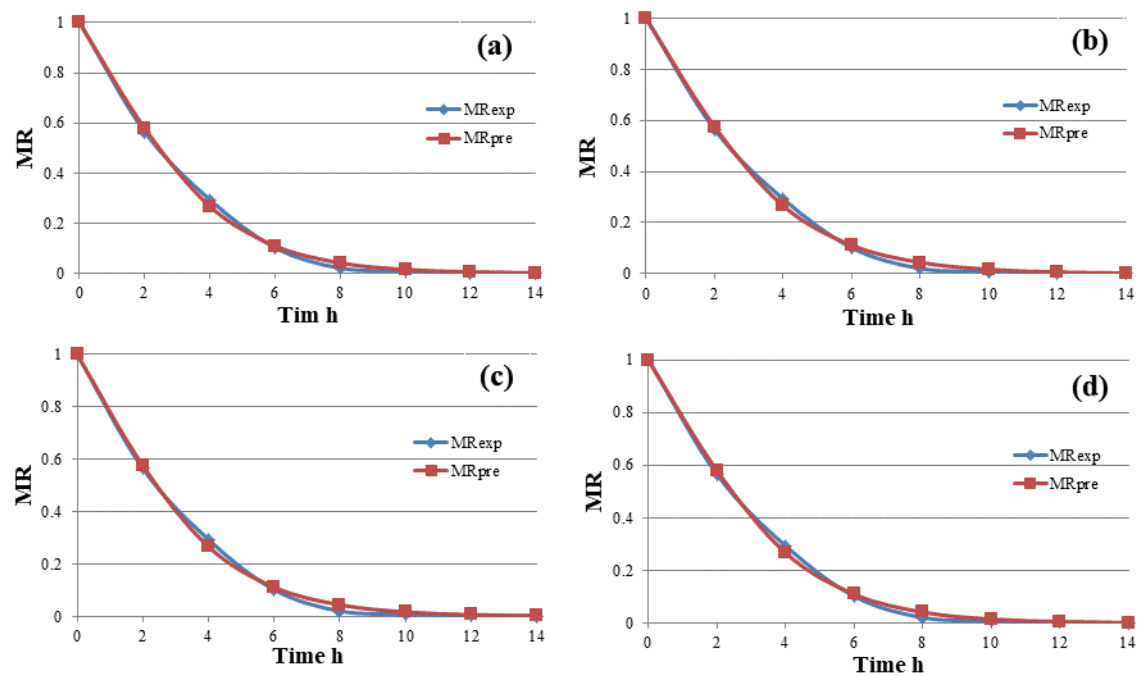

Figure-9.

IFCSD thin layer models comparison of experimental and calculated MR versus drying time, a-

Page model, b- Approximation diffusion model, c- Verma et al. model and d- Midilli Kacuk model.

Statistical analysis was done to select the most appropriate thin-layer empirical model for drying apple slices for both IFCSD and OSD systems. The analysis was conducted to decide the most suitable model with the highest value of statistical parameter, $R^{2}$ (Equation 4) and the lowest values of $X^{2}$ (Equation 5) and RMSE (Equation 6).

Table 2 shows all constants values $(k, n, a, b, c, g)$ of the eleven models received by fitting the experimental data to the thin layer drying models and the results of statistical parameters calculated by Equations 4, 5 and 6 for IFCSD apple slices drying. The same results for OSD apple slices drying thin layer models are listed in Table 3. 

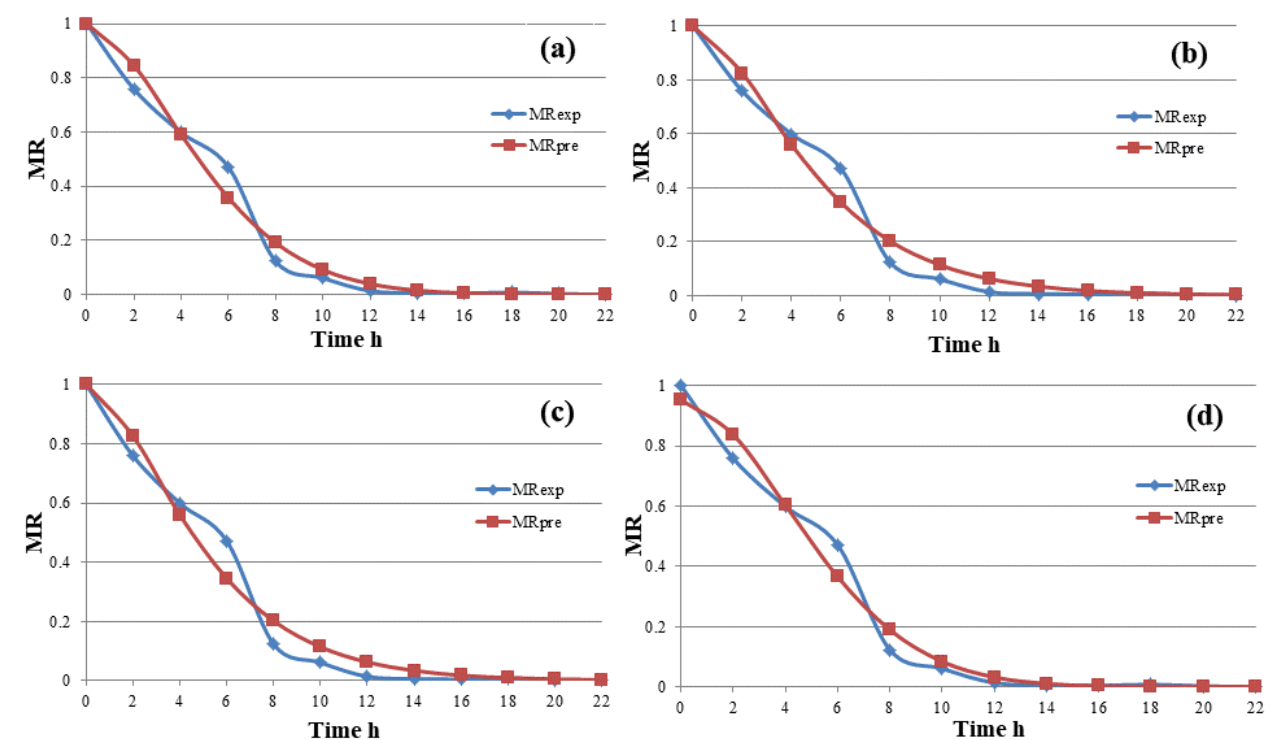

Figure-10.

OSD thin layer models comparison of experimental and calculated MR versus drying time, a- Page model,

b- Approximation diffusion model, c- Verma et al. model and d- Midilli Kacuk model.

Table-2.

Thin layer models and statistical parameters for IFCSD system

\begin{tabular}{|c|c|c|c|c|}
\hline Model No & Model Constants & $R^{2}$ & $X^{2}$ & RMSE \\
\hline 1 & $k=0.329555933$ & 0.991268274 & 0.001147879 & 0.031692172 \\
\hline 2 & $k=0.226979419 ; n=1.271372879$ & 0.998454327 & 0.001147879 & 0.013334008 \\
\hline 3 & $k=0.299548934 ; n=1.100173944$ & 0.991268274 & 0.001147879 & 0.031692172 \\
\hline 4 & $k=0.334477339 ; a=1.018914216 ; c=0$ & 0.991696734 & 0.001091553 & 0.030904836 \\
\hline 5 & $k=0.334477655 ; a=1.018913915$ & 0.991696734 & 0.001091553 & 0.030904836 \\
\hline 6 & $\begin{array}{l}k_{0}=0.334477516 ; k_{l}=0.33448328 ; a=0.971085939 ; b= \\
0.047828017\end{array}$ & 0.991696734 & 0.001091553 & 0.030904836 \\
\hline 7 & $k=0.329555998 ; a=1.000455506$ & 0.991268274 & 0.001147879 & 0.031692172 \\
\hline 8 & $k=10.44187754 ; n=0.032031965 ; a=1.018966493 ; b=0$ & 0.991696729 & 0.001091554 & 0.001091554 \\
\hline 9 & $k=0.563936824 ; a=36.69902136 ; b=1.019499207$ & 0.998267062 & 0.000227813 & 0.014118658 \\
\hline 10 & $k=0.556494214 ; a=15.38929328 ; g=0.583274938$ & 0.998265311 & 0.000228043 & 0.01412579 \\
\hline 11 & $k=0.225359199 ; n=1.274744729 ; a=0.997288362 ; b=0$ & 0.998462284 & 0.000202149 & 0.013299646 \\
\hline
\end{tabular}

Table-3.

Thin layer models and statistical parameters for OSD system

\begin{tabular}{l|l|l|l|l}
\hline Model No & Model Constants & $\boldsymbol{R}^{2}$ & $\boldsymbol{X}^{2}$ & $\boldsymbol{R} \boldsymbol{M S E}$ \\
\hline 1 & $k=0.185372091$ & 0.944946791 & 0.00701093 & 0.080166616 \\
\hline 2 & $k=0.05374541 ; n=1.648155152$ & 0.980767691 & 0.002449201 & 0.047382497 \\
\hline 3 & $k=0.224659809 ; a=0.825123511$ & 0.944946791 & 0.00701093 & 0.080166616 \\
\hline 4 & $k=0.195515452 ; a=1.068250151 ; c=0$ & 0.949490233 & 0.006432331 & 0.076787391 \\
\hline 5 & $k=0.195511622 ; a=1.06829507$ & 0.949490237 & 0.006432331 & 0.076787388 \\
\hline 6 & $k_{0}=0.195511394 ; k_{l}=0.195509285 ; a=1.042510353 ; b=$ & 0.949490237 & 0.006432331 & 0.076787388 \\
\hline
\end{tabular}




\begin{tabular}{l|l|l|l|l}
\hline & 0.025784432 & & & \\
\hline 7 & $k=0.185372151 ; a=1.000582591$ & 0.944946791 & 0.00701093 & 0.080166616 \\
\hline 8 & $k=10.54933138 ; n=0.018533087 ; a=1.068296012 ; b=0$ & 0.949490237 & 0.006432331 & 0.076787388 \\
\hline 9 & $k=0.368317807 ; a=55.22138184 ; b=1.018224175$ & 0.975515618 & 0.003118044 & 0.053462198 \\
\hline 10 & $k=0.364296389 ; a=25.32773832 ; g=0.379085995$ & 0.975509326 & 0.003118845 & 0.053469067 \\
\hline 11 & $k=0.036867711 ; n=1.81842681 ; a=0.953094078 ; b=0$ & 0.982261468 & 0.002258971 & 0.045505205 \\
\hline
\end{tabular}

According to the achieved statistical parameters from empirical and calculated data IFCSD apple slices drying $R^{2}$ fluctuated form 0.991268 up to $0.998462, X^{2}$ from 0.000228 up to 0.001148 and $R M S E$ from 0.001091 up to 0.031692 . For OSD apples drying $R^{2}$ fluctuated form 0.980768 up to $0.944947, X^{2}$ from 0.002449 up to 0.007011 and $R M S E$ from 0.047382 up to 0.080167 . All data which obtained from the statistical analysis coefficients are dimensionless. In the case of IFCSD system all models provide comparable god description of experimental data; the differences are negligible. However, in the case of OSD system more parametric models such as Midilli and Kucuk, Verma et al and approximation of diffusion provide better results than others.

\section{Conclusions}

In this study, the drying behavior of apple slices was experimentally and mathematically investigated under open sun drying and indirect forced cabinet solar drying. Changes in ambient conditions such as temperature, air relative humidity, and the presence of the pollutant in the air during the day can significantly affect the performance of IFCSD and OSD drying time and dry product quality. The Color and taste, which are among the quality indicators of dried products (dried apples) which are reduced by the sediment of air pollutants and radiation of sunlight on pieces of dried apples in the OSD drying system, which is clearly visible as a result of this research. In locations with dry climate such as Afghanistan, dried product rehydration during the processing do not represent a significant issue. However, in locations with higher air humidity, this hazard can be quite significant since water activity of the dried product can reach values suitable for microorganisms' reproduction.

Drying in an IFCSD system has a 44\% efficiency of drying time compared to drying in OSD system. In the first 8 hours of the experimental day, the weight of the sample was reduced to about $80 \%$ in IFCSD and up to $45 \%$ in OSD, which shows the effectiveness of IFCSD against the OSD.

In the case of IFCSD system all 11 studied models provided comparable god description of experimental data because of stable experimental conditions in the IFCSD system. However, in the case of OSD system more parametric models such as Midilli and Kucuk provide better results than others, because of experimental data scattering.

\section{References}

[1] M. Villamiel, J. Gamboa, A. C. Soria, E. Riera, J. V. García-Pérez, and A. Montilla, "Impact of power ultrasound on the quality of fruits and vegetables during dehydration," Physics Procedia, vol. 70, pp. 828-832, 2015. Available at: https://doi.org/10.1016/j.phpro.2015.08.169.

[2] A. Kaleta, K. Górnicki, R. Winiczenko, and A. Chojnacka, "Evaluation of drying models of apple (var. Ligol) dried in a fluidized bed dryer," Energy Conversion and Management, vol. 67, pp. 179-185, 2013. Available at: https://doi.org/10.1016/j.enconman.2012.11.011.

[3] E. K. Akpinar, Y. Bicer, and F. Cetinkaya, "Modelling of thin layer drying of parsley leaves in a convective dryer and under open sun," Journal of Food Engineering, vol. 75, pp. 308-315, 2006. Available at: https://doi.org/10.1016/j.jfoodeng.2005.04.018.

[4] ANNGO, "Afghanistan national nursery growers organization catalogue 2013-2014," 2013.

[5] M. E. Sormoli and T. A. Langrish, "Spray drying bioactive orange-peel extracts produced by Soxhlet extraction: Use of WPI, antioxidant activity and moisture sorption isotherms," LWT-Food Science and Technology, vol. 72, pp. 1-8, 2016. Available at: https://doi.org/10.1016/j.lwt.2016.04.033.

[6] M. Zhou, Q. Chen, J. Bi, Y. Wang, and X. Wu, "Degradation kinetics of cyanidin 3-O-glucoside and cyanidin 3-O-rutinoside during hot air and vacuum drying in mulberry (Morus alba L.) fruit: A comparative study based on solid food system," Food Chemistry, vol. 229, pp. 574-579, 2017. Available at: https://doi.org/10.1016/j.foodchem.2017.02.131.

[7] D. Jain and P. B. Pathare, "Study the drying kinetics of open sun drying of fish," Journal of Food Engineering, vol. 78, pp. 1315-1319, 2007. Available at: https://doi.org/10.1016/j.jfoodeng.2005.12.044.

[8] A. G. M. B. Mustayen, S. Mekhilef, and R. Saidur, "Performance study of different solar dryers: A review," Renewable and Sustainable Energy Reviews, vol. 34, pp. 463-470, 2014. Available at: https://doi.org/10.1016/j.rser.2014.03.020.

[9] A. M. Ershad, R. J. Brecha, and K. Hallinan, "Analysis of solar photovoltaic and wind power potential in Afghanistan," Renewable Energy, vol. 85, pp. 445-453, 2016. Available at: https://doi.org/10.1016/j.renene.2015.06.067.

[10] A. R. P. Kingsly, H. R. Meena, R. K. Jain, and D. B. Singh, "Shrinkage of ber (Zizyphus mauritian L.) fruits during sun drying," Journal of Food Engineering, vol. 79, pp. 6-10, 2007. Available at: https://doi.org/10.1016/j.jfoodeng.2006.01.019.

[11] S. I. Anwar and G. N. Tiwari, "Evaluation of convective heat transfer coefficient in crop drying under open sun drying conditions," Energy Conversion and Management, vol. 42, pp. 627-637, 2001. Available at: https://doi.org/10.1016/S01968904(00)00065-0. 
[12] D. Jain and G. N. Tiwari, "Thermal aspects of open sun drying of various crops," Energy, vol. 28, pp. 37-54, 2003. Available at: https://doi.org/10.1016/S0360-5442(02)00084-1.

[13] A. El Khadraoui, S. Bouadila, S. Kooli, A. Farhat, and A. Guizani, "Thermal behavior of indirect solar dryer: Nocturnal usage of solar air collector with PCM," Journal of Cleaner Production, vol. 148, pp. 37-48, 2017. Available at: https://doi.org/10.1016/j.jclepro.2017.01.149.

[14] M. Sandali, A. Boubekri, D. Mennouche, and N. Gherraf, " Improvement of a direct solar dryer performance using a geothermal water heat exchanger as supplementary energetic supply. An experimental investigation and simulation study," Renewable Energy, vol. 135, pp. 186-196, 2019. Available at: https://doi.org/10.1016/j.renene.2018.11.086.

[15] S. Shamekhi-Amiri, T. B. Gorji, M. Gorji-Bandpy, and M. Jahanshahi, "Drying behaviour of lemon balm leaves in an indirect double-pass packed bed forced convection solar dryer system," Case studies inTthermal Engineering, vol. 12, pp. 677-686, 2018. Available at: https://doi.org/10.1016/j.csite.2018.08.007.

[16] S. Seiiedlou, H. R. Ghasemzadeh, N. Hamdami, F. Talati, and M. Moghaddam, "Convective drying of apple: Mathematical modeling and determination of some quality parameters," International Journal of Agriculture and Biology, vol. 12, pp. 171178, 2010. Available at: http://www.fspublishers.org.

[17] S. R. Shewale, D. Rajoriya, and H. U. Hebbar, "Low humidity air drying of apple slices: Effect of EMR pretreatment on mass transfer parameters, energy efficiency and quality," Innovative Food Science \& Emerging Technologies, vol. 55, pp. 1-10, 2019. Available at: https://doi.org/10.1016/j.ifset.2019.05.006.

[18] L. Blanco-Cano, A. Soria-Verdugo, L. M. Garcia-Gutierrez, and U. Ruiz-Rivas, "Modeling the thin-layer drying process of Granny Smith apples: Application in an indirect solar dryer," Applied Thermal Engineering, vol. 108, pp. 1086-1094, 2016. Available at: https://doi.org/10.1016/j.applthermaleng.2016.08.001.

[19] K. Sacilik, R. Keskin, and A. K. Elicin, "Mathematical modelling of solar tunnel drying of thin layer organic tomato," Journal of food Engineering, vol. 73, pp. 231-238, 2006. Available at: https://doi.org/10.1016/j.jfoodeng.2005.01.025.

[20] H. Atalay, M. T. Coban, and O. Kincay, "Modeling of the drying process of apple slices: Application with a solar dryer and the thermal energy storage system," Energy, vol. 134, pp. 382-391, $2017 . \quad$ Available at: https://doi.org/10.1016/j.energy.2017.06.030.

[21] G. M. Kituu, D. Shitanda, C. L. Kanali, J. T. Mailutha, C. K. Njoroge, J. K. Wainaina, and V. K. Silayo, "Thin layer drying model for simulating the drying of Tilapia fish (Oreochromis niloticus) in a solar tunnel dryer," Journal of Food Engineering, vol. 98, pp. 325-331, 2010. Available at: https://doi.org/10.1016/j.jfoodeng.2010.01.009.

[22] İ. T. Toğrul and D. Pehlivan, "Modelling of thin layer drying kinetics of some fruits under open-air sun drying process," Journal of Food Engineering, vol. 65, pp. 413-425, 2004. Available at: https://doi.org/10.1016/j.jfoodeng.2004.02.001

[23] K. B. Koua, W. F. Fassinou, P. Gbaha, and S. Toure, "Mathematical modelling of the thin layer solar drying of banana, mango and cassava," Energy, vol. 34, pp. 1594-1602, 2009. Available at: https://doi.org/10.1016/j.energy.2009.07.005.

[24] E. K. Akpinar and Y. Bicer, "Mathematical modelling of thin layer drying process of long green pepper in solar dryer and under open sun," Energy Conversion and Management, vol. 49, pp. 1367-1375, 2008. Available at: https://doi.org/10.1016/j.enconman.2008.01.004.

[25] Y. Bahammou, Z. Tagnamas, A. Lamharrar, and A. Idlimam, "Thin-layer solar drying characteristics of Moroccan horehound leaves (Marrubium vulgare L.) under natural and forced convection solar drying," Solar Energy, vol. 188, pp. 958-969, 2019. Available at: https://doi.org/10.1016/j.solener.2019.07.003.

[26] Y. Zhou and Y. Jin, "Mathematical modeling of thin-layer infrared drying of dewatered municipal sewage sludge (DWMSS)," Procedia Environmental Sciences, vol. 31, pp. 758-766, 2016. Available at: https://doi.org/10.1016/j.proenv.2016.02.066.

[27] I. Ali, L. Abdelkader, B. El Houssayne, K. Mohamed, and L. El Khadir, "Solar convective drying in thin layers and modeling of municipal waste at three temperatures," Applied Thermal Engineering, vol. 108, pp. 41-47, 2016. Available at: https://doi.org/10.1016/j.applthermaleng.2016.07.098.

[28] S. Lahsasni, M. Kouhila, M. Mahrouz, A. Idlimam, and A. Jamali, "Thin layer convective solar drying and mathematical modeling of prickly pear peel (Opuntia ficus indica)," Energy, vol. 29, pp. 211-224, 2004. Available at: https://doi.org/10.1016/j.energy.2003.08.009.

[29] L. A. Mohamed, C. E. Kane, M. Kouhila, A. Jamali, M. Mahrouz, and N. Kechaou, "Thin layer modelling of Gelidium sesquipedale solar drying process," Energy Conversion and Management, vol. 49, pp. 940-946, 2008. Available at: https://doi.org/10.1016/j.enconman.2007.10.023. 